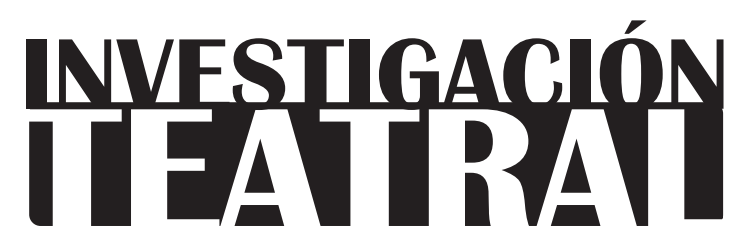

Revista de artes escénicas y performatividad

Vol. 9, Núm. 13

abril-septiembre 2018

Segunda época

ISSN impreso: 1665-8728

ISSN electrónico: 2594-0953

Universidad Veracruzana

\title{
La labor afectiva del duelo: ofrendas, pérdidas y desapariciones en Guerrero
}

\author{
Anne W. Johnson*
}

\footnotetext{
* Departamento de Ciencias Sociales y Políticas, Universidad Iberoamericana, México.

e-mail:anne.johnson@ibero.mx
}

Recibido: 14 de septiembre de 2017

Aceptado: 31 de enero de 2018 
INVESTIGACIÓNTEATRAL

Revista de artes escénicas y performatividad

Vol. 9, Núm. 13

abril-septiembre 2018
La labor afectiva del duelo: ofrendas,

pérdidas y desapariciones en Guerrero

Anne W. Johnson

\title{
La labor afectiva del duelo: ofrendas, pérdidas y desapariciones en Guerrero
}

\section{Resumen}

En este ensayo intento dar pistas para comprender la labor afectiva del duelo en dos contextos. Primero, retomo la construcción de las "ofrendas nuevas" en Teloloapan, Guerrero, como una expresión de luto y manera de manejar la pérdida de un ser querido. A continuación volteo la mirada a la emergencia del movimiento social alrededor de la desaparición forzada de cuarenta y tres normalistas en Iguala, Guerrero, expresión de una violencia en la cual está implicado el Estado mexicano y que, a la vez que enmarca la acción política en la experiencia de dolor y pérdida, demuestra los límites del proceso de duelo. El análisis de ambos casos me permite reflexionar sobre el duelo como una labor afectiva que, en distintas situaciones, produce distintos efectos culturales, psicológicos, sociales y políticos.

Palabras clave: duelo, afecto, movimiento social, Guerrero, materialidad, memoria.

\section{The affective labor of grieving: ofrendas, loss and disappearance in Guerrero, Mexico.}

\begin{abstract}
In this essay, I try to understand the affective labor of grief in two contexts. First, I take up the construction of the "ofrendas nuevas" in Teloloapan, Guerrero as an expression of mourning and a means of managing the loss of a loved one. I then turn to the emergence of the social movement that has grown up around the forced disappearance of 43 teacher-training students in Iguala, Guerrero, an expression of state-complicit violence that demonstrates the limits of the grief process, as it simultaneously frames political action in the experience of pain and loss. The analysis of both cases allows me to reflect on grief as affective labor that produces distinct cultural, psychological, social and political effects.
\end{abstract}

Keywords: Grief, Affect, Social movements, Materiality, Memory, Guerrero, Mexico. 


\section{La labor afectiva del duelo: ofrendas, pérdidas y desapariciones en Guerrero}

\section{Introducción}

$\mathrm{E}$ n este ensayo intento dar pistas para comprender el duelo en dos contextos. Primero, retomo la construcción de las "ofrendas nuevas" en Teloloapan, Guerrero, como una expresión de luto y manera de manejar la pérdida de un ser querido. Más adelante volteo la mirada a la emergencia del movimiento social alrededor de la desaparición forzada de 43 normalistas en Iguala, en el mismo estado; expresión de una violencia en la cual está implicado el Estado y que, a la vez que enmarca la acción política en la experiencia de dolor y pérdida, demuestra los límites del proceso de duelo. El análisis de ambos casos me permite reflexionar sobre el duelo como una labor afectiva que produce distintos efectos culturales, psicológicos, sociales y políticos. ${ }^{1}$

Las ofrendas llenan el vacío que deja la ausencia del difunto con un conjunto de objetos prostéticos. Forman parte de un proceso de duelo que permite a los dolientes manejar sus experiencias de pérdida y salir adelante. Las acciones que emprenden las madres y padres de los desaparecidos de Ayotzinapa, por otra parte, giran alrededor del lema "nos faltan 43" y resaltan las ausencias que no se pueden resarcir a través del proceso psicológico "normal"

1 Agradezco enormemente a los participantes en el coloquio "Teatro y abandono", organizado por Rodrigo Parrini y Eduardo Bernal, y también a los participantes en el seminario "Memoria Colectiva" patrocinado por la Coordinación Nacional de Antropología del INAH. Sus comentarios sobre las inquietudes expresadas en este texto fueron invaluables. Por otra parte, fueron de gran ayuda los comentarios del dictaminador anónimo de este texto para aclarar varios conceptos y argumentos. 
del duelo, ya que apelan también a vacíos políticos y sociales. Concluyo este ensayo con una consideración de la relación entre duelo, materialidad y memoria, sugiriendo un replanteamiento de las posibilidades productivas de la melancolía.

\section{La muerte en Teloloapan}

El estudio de la construcción de las ofrendas nuevas en Teloloapan permite entrever cómo ciertas prácticas performativas implican la construcción de - y participación en - una malla de relaciones que involucran a otros humanos y objetos materiales. Me enfocaré en un conjunto de acciones que conmemora la muerte en Teloloapan, Guerrero, pueblo viejo de trasfondo nahua ubicado en la región norte del estado que, en voz de sus pobladores, "ya no" es una comunidad indígena.

La producción de "las ofrendas nuevas" vincula a teloloapenses vivos y muertos con objetos materiales en una malla de conocimientos, acciones y percepciones que les permiten moverse en un mundo precario. La ofrenda es, como veremos, un proceso más que un producto. Y en el centro de este proceso está el duelo. Espero mostrar cómo la creación de la ofrenda forma parte de una labor afectiva que moviliza personas, cosas y fuerzas, elementos duraderos y efímeros, como una manera de enfrentar la pérdida.

Cuando llegué al pueblo en agosto de 1999 para hacer trabajo de campo como parte de mi tesis de doctorado en antropología social, planeaba estudiar las representaciones colectivas de la Guerra de Independencia en la región norte del estado de Guerrero, concentrándome en la tradición de los Diablos de Teloloapan como parte de una poética historia local, construida ante la imposición de una historia y una identidad nacionales (ver Johnson, Diablos, insurgentes). Más o menos seguí con el proyecto original, pero como suele suceder (y como debe suceder), la "realidad" terminó transformando y ampliando mis temas de investigación.

Don Fidel de la Puente Fabián, encargado de la tradición de los Diablos, mascarero y mi interlocutor principal, murió repentinamente en marzo de 2000 a los setenta años; como consecuencia, el manejo de la muerte en el pueblo encontró un espacio dentro de mi trabajo. Las prácticas que envuelven este manejo se llevan a cabo en distintos momentos a partir del fallecimiento del sujeto, pero aquí me enfocaré en las "ofrendas nuevas", (aclarando que, como de algún modo me había convertido en miembro de la familia de Don Fidel, mi análisis de estos procesos no se puede separar del recuerdo corporal de haber participado en las labores que los sostenían). 


\section{La "ofrenda nueva"}

Cuánto alboroto. Cuando me muera, mejor envuélvanme en un petate, y échenme al hoyo Doña Gloria, prima de Don Fidel.

El primer año después de la muerte de una persona, se arma una ofrenda muy vistosa y compleja. Se llama la "ofrenda nueva" y no se repite con la misma espectacularidad en años posteriores. Una semana antes de la celebración de los Días de Muertos, se publica una lista de personas que han fallecido en el curso del año en el periódico local para que todo el público pueda visitar las ofrendas, evaluarlas y compararlas, además de acompañar a las familias en su proceso de luto. Después de las dos noches de visita a las ofrendas - el 31 de octubre para los difuntos chiquitos y el $1^{\circ}$ de noviembre para los difuntos grandes-, todas las familias llevan las flores de las ofrendas a las tumbas de sus familiares en el panteón, donde siguen compartiendo los alimentos entre ellos y con sus muertos.

Vale la pena ofrecer más detalles sobre el proceso de construcción de estas ofrendas (únicas, hasta donde sé, en Guerrero y en México), ya que es la labor afectiva y performativa involucrada en su producción lo que despliega un conjunto de fuerzas y objetos que les dan su poder y particularidad. Una de las características que distingue a la ofrenda teloloapense es el "cielo" de papel que cubre el techo y las paredes del cuarto o espacio donde se arma. Normalmente hay una imagen religiosa central de algún santo o acontecimiento bíblico, prestada a la familia por algún dueño o párroco, o en su caso dibujada o esculpida en escala humana o un poco más grande.

Para las difuntas, se coloca la imagen de una virgen, y para los difuntos hombres, un santo o una imagen de Cristo. La representación bíblica es acompañada por una imagen del fallecido - puede ser una fotografía u otra representación iconográfica-, así como por objetos que representan los gustos o actividades de la persona en vida, además de plantas, pilares, tierra, "llorones" (estatuas de yeso de niños llorando), flores y velas. Suele además colocarse una representación de la tumba del difunto, un soneto o poema en su honor y en ocasiones bordados en tela u otras artesanías. Recientemente, se han empezado a incorporar varios elementos multimediáticos como luces, sonido y videos o diapositivas proyectadas.

Muchas familias contratan a un ofrendero para crear este elaborado ensamblaje. Los gastos pueden llegar a ser enormes, igual que el tiempo invertido en la construcción. A veces la gente se refiere a la exhibición de las ofrendas como un "concurso," aunque no concluye en una premiación. Algunos ofrenderos son artesanos por oficio, mientras que otros son personas conocidas por su creatividad o bien por su vocación religiosa. 


\section{La ofrenda de Don Fidel}

Para construir la ofrenda se trabajó primero con el papel, cocinando una mezcla de engrudo para pegar cientos de pliegos y así crear el cielo; a continuación se le arrugó y se le ataron nudos para generar la textura necesaria y se pintó en azul de distintos tonos. Se decidió adoptar como imagen principal la de Cristo, Dimas y Gestas crucificados en El Calvario, usando como modelo un calendario que don Fidel tenía colgado en su cocina. Se pidieron prestadas las figuras de Dimas y Gestas a un vecino, pero el Cristo se elaboró con papel maché aprovechando los innumerables ejemplares de La Prensa que don Fidel había almacenado en su casa.

Se completó el escenario con armazones y otros materiales básicos: pintura, iluminación (la luz negra sobre colores fosforescentes se ha vuelto muy popular en los últimos años), rocas, agua y plantas. Después se colocaron los objetos relacionados con el difunto: fotografías, la tumba, el soneto, los bordados, las miniaturas y los objetos preferidos. Se puso una calaca o esqueleto de poliestireno pintado de amarillo fosforescente, y colgando de uno de sus brazos se colocó el morral de piel que solía usar el difunto con dos botellas de Coca-Cola de vidrio en su interior. A los pies de este personaje, un tanto espeluznante, se colocaron varios diablos en miniatura y frente a él un maniquí también vestido de diablo. Finalmente se complementó la ofrenda con flores, velas y pan, cuyo número aumentaba conforme llegaban los espectadores. Un grupo de jóvenes vestidos de diablos hacía guardia afuera de la ofrenda, cada uno con un ramo de flores. La familia ofreció ponche caliente y pan recién horneado a los concurrentes.

\section{Ofrenda y memoria}

La creación de la ofrenda forma parte del proceso de manejo de la aflicción. Las ofrendas son sitios de memoria (ver Nora, "Between Memory") que se conforman conjugando varias cosas. Primero se necesita un espacio dentro del hogar del difunto o sus parientes; segundo, la acumulación y arreglo de objetos materiales: fotografías, figuras religiosas, textos, medios visuales y auditivos, comida, flores, etcétera; tercero, los elementos teatrales como el cielo de papel o tela, las luces, pintura, bocinas, soportes estructurales y otros elementos que forman un telón de fondo para los objetos exhibidos (y coadyuvan a convertir un espacio doméstico en un lieux de memoire más íntimo); y finalmente, los cuerpos de quienes crean la ofrenda mediante la transformación del espacio, cuyos recuerdos confieren significado a todo lo demás. Podría considerarse aún un quinto elemento fundamental, más ausencia que presencia: es percibido como el fantasma del difunto o simplemente su ausencia; la fuerza del deseo ocasionado por la pérdida es lo que impulsa la ofrenda. 
"El espacio contiene el tiempo comprimido", escribió Bachelard, "para eso es el espacio" (La Poética, 31). Crear una ofrenda es una manera de movilizar el espacio doméstico, convertir un cuarto en un contenedor de tiempo comprimido, rellenarlo con dispositivos mnemónicos diseñados para representar los elementos más sobresalientes de la identidad del difunto (según su familia) y evocar los recuerdos del público.

Los objetos de la ofrenda cumplen diversas funciones. Por un lado están aquellos que intentan establecer algún tipo de intercambio: comida, velas, flores, etcétera. En segundo lugar, los que tienen una función mimética (copias del difunto cuyo poder mágico se deriva de su semejanza con él o ella), como pueden ser las efigies, fotografías, videos, figuras en tres dimensiones o cualquier otra representación del difunto. Finalmente, podemos considerar ciertos accesorios cuyo poder se deriva de la segunda ley de la magia simpática -el contagio-, es decir, objetos que estuvieron en contacto directo con el difunto (como sus ropas o accesorios) y absorbieron de ese modo su magia. Los últimos dos tipos sustituyen al sujeto ausente de uno u otro modo.

También suele haber copias indexicales en pequeña escala de las actividades o lugares asociados con el difunto. Se trata de miniaturas en las que, siguiendo a Bachelard, "los valores se condensan y se enriquecen [...]; uno tiene que ir más allá de la lógica para experimentar qué es grande y qué es pequeño" (138). La reducción en escala nos permite comprender, captar y consumir visualmente lo representado, reduciendo "el espacio del sujeto y el espacio de lo social" (Stewart, On Longing 68), comprimiendo y materializando la historia vital del sujeto en un objeto diminuto que, a pesar de su tamaño, puede condensar detalles que hacen entrar al espectador dentro del objeto y dentro de sus propios recuerdos.

Según Serementakis, la memoria es "una práctica culturalmente mediada que se activa a través de acciones corpóreas y objetos semánticamente densos” (Serementakis, On Longing 9). Un objeto de ofrenda "semánticamente denso" se puede entender como una próstesis del sujeto, "un elemento foráneo que reconstruye lo que no se puede parar solo, al mismo tiempo sosteniendo y extendiendo a su anfitrión” (Wigley, en González "Autotopographies" 135). González denomina a este tipo de colección de objetos "autotopografías" o "museos del ser":

Existiendo en el contínuum de monumento y microcosmos, esta colección, este arreglo o almacenamiento de objetos simbólicamente significativos representa una identidad personal en relación a una red social más amplia de significados y funciones para anclar la imagen autoreflexiva del sujeto dentro de un cosmos local y terrenal. En la creación de una autotopografía - que no incluye toda la propiedad personal sino solamente aquellos objetos que significan una identidad "individual" - se hace 
una llamada al mundo material para presentar un mapa físico de memoria, historia y creencia. El objeto autobiográfico entonces se convierte en mecanismo prostético: una adición, un rastro y un sustituto por los aspectos intangibles de deseo, identificación y relaciones sociales (134).

En este sentido, los objetos de una ofrenda coleccionados por los miembros de la familia y no por el sujeto mismo, podrían entenderse como biotopografías. Al igual que sucede en cualquier otra historia, la historia de vida representada en la ofrenda está llena de silencios (ver Trouillot, Silencing the Past). Nunca "terminada," la ofrenda representa entonces la percepción parcial y muchas veces nostálgica de los otros acerca de un sujeto; crea un espacio tanto para recordar como para olvidar, forjando "un vínculo metonímico con eventos pasados y personas ausentes" (González, "Autotopographies" 134). Las brechas en la ofrenda exigen la participación corpórea para completar el circuito mnemónico. Como escribe nuevamente Serementakis,

El paisaje sensorial y sus objetos-dotados-de-significado conllevan una sedimentación emocional e histórica que puede provocar y encender gestos, discursos y acciones; acciones que abren la estratigrafía de estos objetos. Así, el entorno de la cultura material no es ni estable ni fijo, sino inherentemente transitivo, exigiendo conexión y completitud por el público ("The Memory" 7).

Pero el otro silencio, más allá de lo que se excluye en el objeto-narrativa, es el de la pérdida. La ausencia del difunto queda subrayada precisamente por la presencia de tantos objetos materiales, así como por el exceso de memoria que éstos suelen invocar. Es en la brecha ominosa entre la materialidad excesiva de la ofrenda y la ausencia palpable del ser querido que se producen el deseo y la memoria: "La memoria es un índice de pérdida" (Davis y Stern, "Introduction to Special" 4), y es dicha pérdida la que anima la ofrenda.

La ausencia se combate, no obstante, mediante la representación cósmica (producto de la fe católica) que permite creer a los vivos que los muertos todavía tienen su lugar en el universo, aunque ya no en la tierra sino en el paraíso. Se recrea así un imaginario que permite un manejo psicológico de la pérdida. Se establece la sobrevivencia del ser desvanecido en el escenario mental estructurado por los recuerdos que evocan los elementos simbólicos de la ofrenda, pero también en el teatro externo de la misma ofrenda, que representa una visión del más allá donde los difuntos están bien acompañados por Jesucristo, la Virgen María y los santos. 


\section{Muerte, ofrendas y violencia}

Estudiar las ofrendas nuevas ha sido una manera de mantenerme informada sobre la cuestión de la mortalidad en Teloloapan: ¿quiénes mueren y de qué? Hace algún tiempo, se construían ofrendas para las personas que morían "de viejo", por enfermedad, accidentes automovilísticos o riñas personales que se tornaban violentas a causa del alcohol. En los últimos años, sin embargo, ha aumentado la cantidad de muertes relacionadas con la violencia vinculada al tráfico de drogas en la región (resalta un número desproporcionado de ofrendas para policías, choferes y taxistas).

Además, gracias a la confluencia de objetos mnemónicos hechos paisajes biotopográficos por los familiares y acompañantes de los difuntos, las conversaciones que tienen lugar en el contexto de las ofrendas se han vuelto una de las pocas formas de comunicación abierta sobre la experiencia de la violencia actual, dado el temor que ésta genera en la población.

\section{El duelo como labor afectiva}

El duelo como proceso creativo nos lleva a reflexionar no solamente sobre su importancia como fenómeno que permite la sanación psicológica del individuo frente a la muerte de un ser querido, sino también sobre las posibilidades del duelo colectivo frente a pérdidas que son consecuencia de la violencia en todas sus expresiones. ¿Cómo pensar, por ejemplo, la experiencia del duelo de los familiares de los desaparecidos, situación que afecta cada vez más a la sociedad mexicana contemporánea?

Si un elemento fundamental de la ofrenda en Teloloapan es el juego entre la presencia y ausencia simultáneas del cuerpo del difunto, ¿cómo procede el proceso de duelo cuando no hay cuerpo? ¿Es posible "cerrar" el proceso? ¿Es necesario? ¿Es deseable? O por otro lado, ¿es posible mantener abierta la crítica y el potencial para la transformación de la realidad, apegándose al lema "vivos los queremos"? Voy a argumentar que, en todo caso, el duelo es performativo: hace algo más allá de tranquilizar la tristeza y rabia del doliente. Despliega las posibilidades del movimiento, del acompañamiento y de la creatividad para construir nuevas relaciones y transformar las viejas, abriendo un espacio para imaginar el futuro con base en la memoria del pasado. 


\section{De duelo y melancolía: Nos faltan 43}

\section{Militancia, claro, entonces, pero duelo también: duelo y militancia. Douglas Crimp, "Mourning and Militancy"}

Como señaló Freud ya hace muchos años en "Duelo y melancolía" (1917), el proceso del duelo suele permitir que una persona que ha sufrido la pérdida de un ser querido en un momento dado, logre superar sus sentimientos de tristeza y enojo con la finalidad de "salir adelante", a pesar del vacío que deja la ruptura de una relación humana, - momentos en los que se evidencia la vulnerabilidad del sujeto ante el otro, cuya ausencia amenaza la integridad del "yo" (Butler, Precarious Life 31) - . La ofrenda nueva llena este vacío por lo menos parcialmente, con objetos e imágenes mnemónicas que sustituyen a la persona ausente. En los rituales de la muerte se reafirman además los lazos sociales entre el sobreviviente y sus semejantes.

No obstante, hay duelos que por distintas razones no terminan con la superación del dolor sino que continúan durante un periodo indeterminado. Freud apela al afecto de la melancolía para ubicar estos casos, que concibe como procesos patológicos de duelo que no siguen su curso "normal", aun cuando admite que los melancólicos poseen "una visión más aguda para la verdad que otras personas que no son melancólicos". Pero con Eng y Vazanjian habrá que preguntarnos "por qué un hombre tiene que estar enfermo antes de poder acceder a una verdad de este tipo" ("Introduction: Mourning Remains" 23).

A este respecto, en muchos casos llama la atención lo que ocurre no solamente con el proceso psíquico individual, sino también con los procesos sociales de duelo. Los sujetos colectivos podrían tener dificultades con los procesos "normales" de manejo de pérdida en ciertas situaciones, sobre todo cuando la muerte ocurre de manera repentina o por violencia. En el caso de la desaparición y el desconocimiento del paradero de la víctima o su cuerpo, estos procesos se tornan aún más complicados y la prolongación es particularmente evidente cuando no hay acceso a la justicia o reconciliación con la muerte. En contraste con el punto de vista de Freud, propongo explorar cómo esta dilatación de las expresiones de duelo puede funcionar como una labor afectiva con efectos sociales y políticos, una estrategia para exigir justicia - la verdadera ausencia - más que una reacción patológica a la pérdida. ${ }^{2}$

2 El duelo crítico y prolongado de las madres y los padres de familia de los normalistas desaparecidos no debe confundirse con la melancolía poética expresada por muchos escritores mexicanos, descrita por Roger Bartra hace muchos años como la añoranza de un "Edén subvertido", de un pasado utópico, campesino y comunitario destruido por el avance inexorable de la modernidad (Bartra, La jaula 31). Al contrario, lejos 
INVESTIGACIÓNTEATRAL

Revista de artes escénicas y performatividad

Vol. 9, Núm. 13

abril-septiembre 2018
La labor afectiva del duelo: ofrendas, pérdidas y desapariciones en Guerrero

Anne W. Johnson

\section{Nuestros hijos con vida}

Después de la noche del 26 de septiembre de 2014, cuando en Iguala, Guerrero (pequeña ciudad que se encuentra a unos sesenta kilómetros de Teloloapan), fueron forzadamente desaparecidos los estudiantes de un grupo de la Normal Rural "Raúl Burgos" de Ayotzinapa, la protesta social y política en contra de la inseguridad y corrupción en el narco-Estado mexicano llegó a configurarse alrededor de este vacío explícito: "nos faltan 43". El lema "Vivos se los llevaron, vivos los queremos", llamada de muchos movimientos de familiares de desaparecidos, anuncia la negación absoluta de la muerte de los normalistas, pero también un rechazo rotundo a la "versión histórica" de los acontecimientos que ofreció el Gobierno Federal mexicano.

Esta resistencia ante la versión "oficial" de los acontecimientos, según la cual los normalistas fueron asesinados y quemados en el basurero de Cocula por miembros del grupo delictivo Guerreros Unidos, en colusión con las autoridades municipales de Iguala, podría ser freudianamente comprendida como una manifestación de melancolía, una obstinada prolongación del duelo a pesar de "las evidencias" de las muertes y la supuesta ubicación de las cenizas de los estudiantes en bolsas de plástico arrojados en un río cercano al basurero. El apego a la búsqueda de sus hijos, el recordatorio constante de que "nos faltan 43", las marchas continuas con las fotos escolares de los estudiantes desaparecidos: ¿no señalan una especie de melancolía? ¿No evidencian aquella enfermedad definida por Samuel Johnson ya en el siglo XVIII como "una especie de locura, en la que la mente se mantiene fija en un solo objeto, un temperamento morboso, pensativo, inquieto"? (en Bowring, A Field Guide 15) ¿Se trata de uno de los casos ejemplares freudianos de duelo enfermizo? ¿Las madres y los padres de los normalistas son "Lloronas" modernas, obsesivamente gritando “Ay, mis hijos!” sin esperanza y sin cesar?

Tal interpretación convendría al Gobierno, cuya versión de lo que ocurrió aquella noche en Iguala intentó negar la complicidad del Estado ("no fue el Estado", aseveró en su rueda de prensa Jesús Murillo Karam, el entonces Procurador de Justicia) y clausurar el movimiento social que ya había crecido alrededor del caso. Si la búsqueda de los padres era un mero síntoma de melancolía, entonces parecería justificado pensar que lo que debieron haber hecho era volverse a llorar en sus tierras, pues ¿quién puede hacerle caso a la Llorona? Al Estado le conviene además pensar en los disidentes como Lloronas para que sean vistos como agentes de su propia desgracia: tal como la mujer de blanco es culpable de su

de un "fatalismo social" esencialista que los atraparía en el pasado y la tradición, estos actores marginados desde el punto de vista de la imposición de normatividades socioculturales, políticas y corpóreas, mantienen una apertura permanente frente al pasado, que les permite exigir un futuro distinto. 
dolor por haber matado a sus propios hijos, los miembros del movimiento son los responsables de las muertes de sus compañeros o parientes por ser pobres, por ser indígenas, por ser "revoltosos".

\section{"Fue el Estado": el duelo desafiante}

Pero el duelo, pensó una vez Walter Benjamin, es una forma de mantener abierta una relación crítica con el pasado en contra del historicismo (como el de aquella "versión histórica") que congela el pasado y no permite su cuestionamiento (en Eng y Kazanjian, "Introduction" 2). Eng y Kazanjian indagan en lo que ellos llaman "la política del duelo", que describen como "aquel proceso creativo que media una relación esperanzada o sin esperanzas entre la pérdida y la historia" (ibíd.). La "pérdida", según estos autores, incluye todo lo aprehendido "por los discursos y las prácticas del duelo, melancolía, nostalgia, trauma y depresión” (ibid.).

Para Benjamin y otros autores, el duelo es un afecto, una relación o una estructura de sentimiento bastante amplia, que no se limita a los desesperados llantos de una Llorona, sino que implica asimismo la labor creativa que emerge de él. No se orienta, por tanto, únicamente hacia el pasado, sino también al futuro en tanto que el acto de narrar la pérdida implica un impulso hacia adelante (13). En contraste con la concepción freudiana de la melancolía como un apego patológico a la pérdida, existen situaciones en las cuales el duelo tiene la posibilidad de convertir la melancolía - experimentada como emoción interna y pasiva - en un afecto capaz de orientar la acción colectiva. ${ }^{4}$

En el movimiento social que creció alrededor del caso Ayotzinapa, el duelo se convirtió en un conjunto de acciones: protesta, denuncia, búsqueda de fosas y cuerpos, narración de la pérdida, recordatorio, entre otras... Acaso las madres y los padres de los normalistas

${ }^{3}$ La leyenda de la Llorona es interesante por muchas razones, pero sobre todo por la posición social que le corresponde al personaje en el imaginario mexicano (en una de sus versiones), como amante, indígena y mujer. Es posible incluso ver en sus incesantes llantos una crítica al sistema colonialista y patriarcal que orilla a las mujeres a tomar decisiones impensables para sobrevivir. ¿El llanto de La Llorona también puede denunciar? El uso de la canción popular homónima, versionada por varios grupos que la utilizan para protestar también por la desaparición de los 43 normalistas, pareciera confirmar las posibilidades críticas de esta figura.

${ }^{4}$ Este tema, sobre todo en relación a las propuestas artísticas que emergen como reacción a la violencia y la pérdida en distintos contextos latinoamericanos, es ampliamente abordado en el libro Cuerpos sin duelo de Ileana Diéguez (2013). 
desaparecidos no se asemejan tanto a la Llorona - excepto en la repetición incesante del lamento provocado por el trauma-, como a Antígona, la heroína griega que rechazó la prohibición del Estado para enterrar el cuerpo de su hermano fallecido en la guerra civil y, como consecuencia, fue condenada a muerte. El grito “inos faltan 43 !" convierte el luto privado en duelo público al irrumpir en los espacios estatales y cívicos, reclamando justicia a un Estado que se deslinda de cualquier responsabilidad.

La labor de Antígona, como la de las madres y padres de Ayotzinapa, es un trabajo afectivo y político. La heroína trágica apelaba — por encima de la ley estatal que dividía a los ciudadanos de los no ciudadanos, o a los dignos de los indignos de un entierro rituala la ley humana que se traduce en el deber familiar respecto a los muertos y el derecho al duelo. Las madres y padres de los normalistas desaparecidos reclaman igualmente los derechos de sus hijos de gozar del estatus de ciudadanos, de ser reconocidos como sujetos (individuales, pero también colectivos) "llorables" — diría Judith Butler-, cuyas muertes, pero sobre todo cuyas vidas, deberían de valer (Butler, Precarious Life 34). Quizás la finalidad última del movimiento, más allá de enterrar dignamente a los desaparecidos, es que primero sean reconocidos como enterrables.

Como la labor afectiva de las ofrendas nuevas en Teloloapan, la labor del duelo emprendido por los participantes en el movimiento social "Nos faltan 43 " depende de una relación ambivalente entre la presencia y la ausencia, la movilización de vínculos emotivo-sociales, un ensamblaje particular de imágenes y objetos y un juego espacial entre movimiento y estasis. Pero estos elementos son empleados de manera distinta y con fines distintos.

\section{Imágenes y objetos melancólicos}

Los desaparecidos de Ayotzinapa tienen un estatus liminar: ni muertos ni vivos, ni presentes ni ausentes, ni cuerpo ni espíritu (Ovando, "La fuerza" 59). Los objetos materiales empleados como parte del movimiento social reflejan de alguna manera dicha ambigüedad. Las armas principales de las madres y padres son las imágenes de sus hijos desaparecidos, que van acompañadas por sus nombres. Tal como ocurre con las ofrendas nuevas, en este contexto la imagen es también memoria y presencia del individual perdido; se convierte en fetiche que actúa mediante la magia mimética de la fotografía para invocar lo que no está. ${ }^{5}$

Los retratos son de los rostros de los estudiantes y evidencian las distintas dinámicas que la cara puede tener: funciona como la "ventana del alma" y como la superficie que per-

\footnotetext{
${ }^{5}$ Según el escritor chileno Pablo Oyarzún, "no hay duelo sin imagen" (en Diéguez, Cuerpos sin duelo 204).
} 
mite reconocer a un sujeto, pero también como una máscara. "El rostro es la evidencia que hace posible la evidencia", decía Levinas (en Taussig, Defacement 224). En algunas de las marchas, los participantes literalmente se han puesto estas fotografías como máscaras, encarnando simbólicamente a los desaparecidos y haciéndolos copartícipes del movimiento, a la vez que materializan su identificación con los sujetos desaparecidos.

Tomadas una por una, cada imagen evoca la pérdida sufrida por una familia, la añoranza de encontrar vivo a un hijo con nombre propio o, en el peor de sus casos, sus restos identificados mediante alguna prueba de ADN. Como señala Taylor en relación con los desaparecidos de la guerra sucia en Argentina, la foto y el ADN "ofrecen radicalmente distintas pruebas de 'presencia, claro, cada uno visibilizando lo que es totalmente inaccesible al otro" (The Archive 176). Ambos funcionan como "evidencias", huellas de una persona perdida, de una relación rota. ${ }^{6}$

Mientras que algunas representaciones artísticas de los rostros de los estudiantes intentan nombrarlos e individualizarlos, las marchas y protestas no giran alrededor de la pérdida de un individuo, sino de cuarenta y tres (y más). El conjunto de imágenes, cuyo despliegue masivo difumina los detalles y las particularidades de cada rostro dada la semejanza estilística de las fotografías, impacta por el horror de imaginar la cantidad de personas simultáneamente desaparecidas. No son propiamente biotopografías, sino necrotopograf ías. ${ }^{7}$

Como en las ofrendas de Teloloapan, los procesos de duelo manifestados en el movimiento social por los cuarenta y tres están íntimamente entrelazados con la creación artística. En las instalaciones creativas que caracterizan al movimiento, el ensamblaje más común es una colección de 43 butacas vacías (a veces en cada butaca se pone una fotografía pegada que, desde luego, no llena la silla ni física ni afectivamente). No se trata nuevamente de la individuación de las víctimas mediante una ofrenda prostética personal, sino de la representación de un vacío colectivo, de un conjunto de ausencias donde debería haber presencias. Las sillas podrían compararse con los muebles que habitaban las casas abandonadas tras los desastres nucleares en Chernobyl o Fukshima, o las de los "pueblos fantasmas" abandona-

${ }^{6}$ Hasta la fecha, las pruebas de adn realizadas por un laboratorio en Alemania a 17 muestras, encontradas supuestamente en Río San Juan, solamente han confirmado la identidad de dos de los normalistas desaparecidos: Alexander Mora Venancio y Jhosivani Guerrero de la Cruz. Peritos del Grupo Interdisciplinario de Expertos Independientes (giei) contratados por la Comisión Interamericana de Derechos Humanos (cidh) desestimaron, sin embargo, la "versión histórica" sostenida por la Procuraduría General de la República (http://prensagieiayotzi.wix.com/giei-ayotzinapa\#!Ayotzinapa-Investigación-y-primeras-conclusiones/ cul3/55edc77cocf23dofeffdgco2/, consultado el 15 de enero del 2016).

${ }^{7}$ Las cifras oficiales cuentan por lo menos 26,ooo desaparecidos en todo el país hasta el día de hoy. De este registro, solamente el dos por ciento está relacionado con una averiguación previa, según datos del Registro Nacional de Personas Extraviadas o Desaparecidas (http://www.animalpolitico.com/2015/06/en-2015-once-personas-desaparecidas-cada-24-horas/, consultado el 15 de enero del 2016). 
dos por las víctimas de la narcoviolencia en Guerrero y otros estados de la República Mexicana, o con los objetos personales desechados en el camino por los migrantes que cruzan clandestinamente las fronteras mexicanas (ver Parrini, "La memoria"). Performativamente, las sillas vacías son "ruinas", parte de aquella clase de objetos que quedan como huellas de destrucción o abyección (Navarro-Yashin, "Affective Spaces" 5).

La lógica del "vivos se los llevaron, vivos los queremos", no obstante, hace que el duelo de los participantes se mezcle con la esperanza (ver Diéguez, Cuerpos sin duelo 33): las butacas podrían ser ocupadas una vez más. No se trata de ofrendas a los muertos para que éstos descansen en paz, sino de objetos mnemónicos que no quieren dejar descansar en paz a los culpables. A diferencia de la labor afectiva de las ofrendas nuevas en Teloloapan, el trabajo afectivo-político de este movimiento social no busca sanar heridas, sino mantenerlas abiertas. El movimiento es eficaz en la medida en que sigue siendo de alguna manera melancólico, para que el caso no se cierre y para que los fantasmas de los 43 sigan acechado a los vivos. Encontrar los cuerpos, identificarlos por nombre y enterrarlos sería matarlos de nuevo y para siempre. Ya no habría nada que exigir al Estado, excepto, quizás, un "Nunca más" que históricamente no ha sido un reclamo particularmente eficaz.

\section{Rutas, centros y márgenes}

Las marchas, como las procesiones funerarias en Teloloapan, trazan rutas de poder y marcan lugares significativos. Pero en lugar de la cartografía que une los puntos casa-iglesia-panteón, la marcha materializa el imaginario cartográfico de una nación hecha de centros y periferias, ligando los márgenes económicos, políticos y sociales con los centros de poder. Las muertes de migrantes en la frontera y de víctimas de la narcoviolencia en la periferia, que ocurren en los márgenes u orillas del Estado, son de suma importancia en tanto que - como argumentan Das y Poole- el Estado es "el sitio en el cual se instituyen mutuamente la biopolítica y la tanatopolítica [...] y [en tanto] que esta relación, que está en el corazón del estado moderno, es más visible en sus márgenes que en su centro" ("State and its" 25). Las marchas son una manera de visibilizar en el centro la violencia estatal que ocurre en la periferia, protestando por la vulnerabilidad de quienes tienen "vidas precarias" y por la distribución desigual del dolor y del luto (Butler, 2004); además de insistir ante las autoridades, por supuesto, que deben aceptar su culpabilidad institucional, pues "Sí fue el Estado".

${ }^{8}$ El choque discursivo entre "No fue el Estado" y "Sí fue el Estado" merece mucho más atención de la que es posible prestarle en este texto, sobre todo porque articula las tensiones entre diversas maneras y perspectivas para entender lo que significa "El Estado": por un lado, se percibe como institución cuasi-mágica que 
Ayotzinapa-Chilpancingo-Ciudad de México es una ruta crítica fundamental, pero también lo son las múltiples rutas de las marchas dentro de la Ciudad de México y las caravanas que se llevan a cabo en otras regiones de la nación. Como he señalado, la intención de acompañamiento es fundamental en las ofrendas nuevas de Teloloapan, pero en el contexto del movimiento social adquiere además una dimensión política: la de solidarizarse y atestiguar. Aquí se manifiesta el poder de la empatía: la pérdida de un hijo es una experiencia con la que casi cualquiera se puede identificar, aunque sea imaginativamente. Diana Taylor afirma que la trasmisión de la experiencia traumática se asemeja al contagio: "uno se contagia de y corporaliza la carga, el dolor y la responsabilidad de conductas y acontecimientos del pasado" (The Archive 168). La empatía y la solidaridad son efectos de la labor afectiva realizada por los integrantes del movimiento, que demuestra de ese modo su eficacia. A través de tal labor se genera comunidad.

La solidaridad empática no es, sin embargo, el único afecto desplegado en las marchas. Este tipo de manifestaciones implican además encuentros con otros sujetos, sobre todo los agentes del Estado. Ellos también emprenden por su parte labores afectivas: a través de su performance corporal y discursivo intentan transformar los ámbitos de protesta social en entornos de miedo y desconfianza, donde se manifiesta explícita y a veces brutalmente el poder del Estado para vigilar, manipular, categorizar y castigar a sus ciudadanos. Las expresiones de la labor afectiva resultan entonces diversas: se dan en las protestas colectivas, desde abajo, pero también en las intervenciones gubernamentales, desde arriba (Thomas y Correa, Affective Labour 224).

En esta revisión del despliegue y distribución del afecto, hay que considerar además la intensa labor al respecto de los grupos delictivos, que muchas veces en colusión con el Estado infunden miedo, incertidumbre y desesperación en los pobladores a través de un conjunto de exhibiciones de violencia extrema que deja huellas imborrables en los cuerpos y las mentes de sus víctimas y testigos.

\section{El rostro de Julio}

Reflexionando nuevamente sobre el papel fundamental que Levinas y otros intelectuales han otorgado al rostro dentro del pensamiento - rostro que al mirarnos puede entenderse como una especie de "evento ético" (en Taussig, Defacement 223) -, el hecho de que uno de

aparentemente está oculta detrás de las operaciones de poder, pero por otro, consiste en un entramado de relaciones, actores e interacciones que permea la vida cotidiana de las personas. Para más sobre esta discusión, ver Abrams ("Notes on the Difficulty"), Trouillot ("The Anthropology") y los distintos textos del libro editado por Sharma y Gupta (2006), entre muchos otros. 
los normalistas asesinados aquella noche haya sido desollado y su cuerpo sin cara arrojado a una calle de Iguala, resulta particularmente significativo (como si señalara justamente el estatus de no-sujetos de los jóvenes estudiantes indígenas). La imagen del cráneo expuesto de Julio César Mondragón forma parte del repertorio simbólico-afectivo del movimiento. Sus familiares y otras personas solidarias han creado la organización "El Rostro de Julio" para contribuir a hallar justicia por su asesinato y a la reaparición de sus compañeros.

En noviembre de 2015, a petición de la familia Mondragón, peritos del Equipo Argentino de Antropología Forense (EAAF), la PGR y la CNDH - entre otras instancias- exhumaron sus restos para realizar una nueva autopsia, ya que las conclusiones de la primera resultaron haber sido inadecuadas. Los restos siguen actualmente en manos de la PGR, y hasta el momento, en enero de 2016, la familia sigue exigiendo el retorno del cuerpo de Julio César a su sepulcro. Se ha denunciado la lentitud y falta de procedimientos adecuados en la realización de la investigación respectiva y señalado que el Estado mexicano revictimiza a las víctimas de manera cotidiana. ${ }^{9}$

Este caso en particular no deja duda de que, aun cuando es posible llevar a cabo de manera normal los rituales de duelo, las víctimas de la violencia estatal no descansan en paz y a sus familiares se les niega la posibilidad de salir del luto.

\section{Reflexiones finales}

La construcción de una ofrenda es, en Teloloapan, un momento dentro del ciclo de prácticas que rodean a la muerte, una manera de marcar la pérdida mediante el despliegue de un conjunto de objetos que evocan recuerdos en todos los allegados del difunto que participan en la creación y consumo de la ofrenda. Se trata de construcciones que convierten la trayectoria de vida de un individuo en una especie de exhibición teatral, que será consumida por un público que puede incluir a familiares y amigos, pero también a la gente de la localidad y — se esperaal espíritu mismo del difunto. A través de la formulación de ensamblajes de imágenes, palabras y objetos, donde todos los sentidos quedan involucrados, la labor afectiva del duelo se sirve de esta actividad para movilizar los procesos de la memoria, contribuyendo a sanar las heridas que deja el rompimiento abrupto de relaciones sociales, individuales y colectivas.

El caso de los familiares de los desaparecidos de Iguala es más complicado, ya que revela los límites del duelo "normal". Por la misma condición liminar que implica el estatuto de "desaparecidos" - la cual además hace eco de la invisibilidad estructural de estos jóvenes

${ }^{9}$ http://elrostrodejulio.org/2016/01/10/por-que-no-ha-sido-reinhumado-el-cuerpo-de-julio-cesar-mondragon-fontes/, consultado el 15 de enero del 2016. 
como estudiantes campesinos e indígenas-, este tipo de difuntos no puede ser objeto de procesos que permitan manejar de manera "sana" la pérdida, a pesar del aire de luto que rodea a las marchas $u$ otras acciones políticas y del despliegue de imágenes y objetos que sustituyen a los ausentes en varios contextos.

La insistencia de las madres y padres de los desparecidos para que el gobierno encuentre "vivos" a sus hijos, reclamo posibilitado por la ausencia de los cuerpos identificables y enterrables, funciona como una crítica al gobierno y una demanda por justicia, no solamente para estos 43 sino para todos los desaparecidos. Como señala Muñoz, para los sujetos queer o pertenecientes a minorías raciales, así como para los familiares de los desaparecidos, el duelo "es un mecanismo que nos ayuda a (re)construir la identidad y llevar a nuestros muertos con nosotros a las variadas batallas que tenemos que librar en su nombre (y en nuestros nombres)" (en Eng y Kazanjian, "Introduction: Mourning Remains" 363).

En vez de buscar consuelo en la creencia en un cielo como el que propone el imaginario católico, representado plásticamente en las ofrendas teloloapenses, los padres de familia de Ayotzinapa apuestan por el sueño de una nación solidaria, construida con base en la equidad y la justicia: "Todos somos Ayotzinapa”. Nos muestran así que el duelo y el activismo no se excluyen mutuamente, los dos ámbitos quedan sujetos en este caso a un juego de presencias y ausencias, de personas y posibilidades. Tanto las ofrendas nuevas de Teloloapan como las marchas y acciones de protesta de los familiares y simpatizantes de los normalistas de Ayotzinapa, visibilizan mediante su labor afectiva un mundo ideal, un mundo como debe o podría ser. Esto implica que el mundo actual se considera incompleto debido a la pérdida o conjunto de pérdidas sufridas.

La pérdida, sobre todo aquella ocasionada por violencia, nos expone como sujetos vulnerables (Butler, Precarious Life 28). Deja truncadas a las personas que la sufren y en general a toda la sociedad. Pero al recordarnos nuestros lazos afectivos con otros seres humanos y la responsabilidad ética que tenemos hacia ellos, aquellos que comparten su duelo - tanto en el luto "normal" como en el duelo indignado- permiten la emergencia de un sentido de comunidad o hasta de un movimiento político colectivo.

\section{Bibliografía}

Abrams, Philip. "Notes on the Difficulty of Studying the State". Journal of Historical Sociology, vol. 1, núm. 1, 1988 [1977], pp. 59-89.

Bachelard, Gaston. La Poética del espacio. Trad. Ernestina De Champourcin. México: Fondo de Cultura Económica, 1975. 
Bartra, Roger. La jaula de la melancolía. Identidad y metamorfosis del mexicano. México: Grijalbo, 1987.

Bowring, Jacky. A Field Guide to Melancholy. Harpenden: Oldcastle Books, 2008.

Butler, Judith. Precarious Life: The Powers of Mourning and Violence. Londres: Verso, 2004.

Das, Veena y Deborah Poole. "State and its Margins: Comparative Ethnographies". Anthropology in the Margins of the State. Eds. Veena Das y Deborah Poole. Santa Fe: School of American Research Press, 2004, pp. 3-34.

Davis, Natalie y Randolph Stern. "Introduction to Special Issue on Memory and Counter-Memory". Representations, vol. 26, 1989, pp. 1-6.

Diéguez, Ileana. Cuerpos sin duelo: Iconografías y teatralidades del dolor. Córdoba, Argentina: Ediciones DocumentA/Escénicas, 2013.

Eng, David L. y David Kazanjian. "Introduction: Mourning Remains". Loss: The Politics of Mourning. Eds. David L. Eng y David Kazanjian. Berkeley - Los Angeles: University of California Press, 2003, pp. 1-28.

Freud, Sigmund. Trabajos sobre metapsicología, duelo y melancolía (Tomo XIV). Buenos Aires: Amorrortu, 1917 [1915].

González, Jennifer A. “Autotopographies”. Prosthetic Territories: Politics and Hypertechnologies. Eds. Gabriel Brahm Jr. y Mark Driscoll. Boulder: Westview Press, 1995.

Johnson, Anne W. Diablos, insurgentes e indios: política y poética de la historia en el Norte de Guerrero. Ciudad de México: Secretaría de la Cultura / Instituto Nacional de Antropología e Historia, 2016.

Navarro-Yashin, Yael. "Affective Spaces, Melancholic Objects: Ruination and the Production of Anthropological Knowledge". Journal of the Royal Anthropological Institute, vol. 15, 2009, pp. 1-18.

Nora, Pierre. "Between Memory and History: Les lieux de memoire". Representations, vol. 26, 1989, pp. 7-25.

Ovando, Pedro. "La fuerza de la desaparición. Notas acerca de la construcción performativa de los símbolos". Diario de Campo, núms. 6-7, 2015, pp. 55-61.

Parrini, Rodrigo. "La memoria como desecho. Las prendas de un ropero para migrantes". Ponencia. Primer Coloquio sobre Memoria Colectiva, Instituto Nacional de Antropología. Ciudad de México, 2015.

Serementakis, C. Nadia. "The Memory of the Senses, Part I" y "The Memory of the Senses, Part II". The Senses Still: Perception and Memory as Material Culture in Modernity. Ed. C. Nadia Serementakis. Chicago-Londres: University of Chicago Press, 1994, pp. 1-43.

Sharma, Aradhana y Akhil Gupta, eds. The Anthropology of the State: A Reader. Malden, MA: Blackwell Publishing, 2006. 
INVESTIGACIÓNTEATRAL

Revista de artes escénicas y performatividad

Vol. 9, Núm. 13

abril-septiembre 2018
La labor afectiva del duelo: ofrendas, pérdidas y desapariciones en Guerrero

Anne W. Johnson

Stewart, Susan. On Longing: Narratives of the Miniature, the Gigantic, the Souvenir, the Collection. Baltimore: The Johns Hopkins University Press, 1993.

Taussig, Michael. Defacement. Public Secrecy and the Labor of the Negative. Nueva York: Routledge, 1999.

Taylor, Diana. The Archive and the Repertoire. Durham: Duke University Press, 2003.

Thomas, James M. y Jennifer G. Correa. Affective Labour: (Dis)assembling Distance and Differenc. Londres-Nueva York: Rowman \& Littlefield International, 2016.

Trouillot, Michel. "The Anthropology of the State in the Age of Globalization: Close Encounters of the Deceptive Kind". Current Anthropology, vol. 42, núm. 1, 2001, pp. 125-138.

Trouillot, Michel. Silencing the Past: Power and the Production of History. Boston: Beacon Press, 1995.

Tuan, Yi-Fu. Space and Place: The Perspective of Experience. Minneapolis: University of Minnesota Press, 1977. 